\title{
Diuretic treatment in decompensated cirrhosis and congestive heart failure: effect of posture
}

\author{
HELMER RING-LARSEN, JENS H HENRIKSEN, \\ CHARLOTTE WILKEN, JANE CLAUSEN, \\ HENRIK PALS, NIELS JUEL CHRISTENSEN
}

\begin{abstract}
The diuretic effect of the supine position was evaluated in six patients with cirrhosis and ascites and six with congestive cardiac failure. After fasting overnight in bed the patients received bumetanide $1 \mathrm{mg}$ intravenously and were then immediately randomly assigned to either bed rest in the supine position or normal daily activity in the upright position for the next six hours. Two days later the procedure was repeated, the patients being assigned to the other posture. The diuretic response was similar in patients with heart failure and cirrhosis, and was significantly greater in the supine than in the upright position: mean $1133 v 626$ $\mathrm{ml} / 6 \mathrm{~h}(\mathrm{p}<0.01)$. The natriuresis was similarly larger during recumbency: mean sodium $96 v 45 \mathrm{mmol}(\mathrm{mEq}) / 6 \mathrm{~h}(\mathrm{p}<0.01)$, and the excreted potassium in six hours was similar in both postures. The glomerular filtration rate was 100 and $66 \mathrm{ml} / \mathrm{min}(\mathrm{p}<0.01)$ and heart rate 76 and 83 beats/min $(p<0.01)$ in the supine and upright positions respectively. Plasma concentrations of noradrenaline, renin, and aldosterone were all raised even when the patient adopted the supine position, and a further significant rise was observed during the upright position.
\end{abstract}

The results suggest that the attenuated response to intravenous bumetanide in the upright position and during normal

Division of Hepatology 233, Hvidovre Hospital, DK-2650, Hvidovre, Denmark HELMER RING-LARSEN, MD, consultant

CHARLOTTE WILKEN, MD, registrar

JANE CLAUSEN, MD, registrar

HENRIK PALS, MD, registrar

Department of Clinical Physiology, Hvidovre Hospital

JENS H HENRIKSEN, MD, consultant

Department of Medicine and Endocrinology, Herlev Hospital, DK-2730, Herlev, Denmark

NIELS JUEL CHRISTENSEN, MD, consultant

Correspondence to: Dr H Ring-Larsen, Medical Department 4, Kommunehospitalet, DK-1399, Copenhagen K, Denmark. daily activity may be due to the activation of several homoeostatic mechanisms that may reduce the excretion of water and salt.

\section{Introduction}

The aim of diuretic treatment is to reduce the sodium and water content of the body, but in patients with oedema or ascites this process has side effects. These are often dose related, and consequently the lowest necessary dose of a diuretic should be used.' Before the introduction of potent loop diuretics bed rest was recommended in oedematous states, as this apparently produced a negative sodium and water balance. The diuretic effect of the supine position, however, has never been critically evaluated and the mechanisms responsible never fully elucidated. The purpose of the present investigation was to quantify the effect of posture on the response to a diuretic and simultaneously to study changes in other possibly important variables.

\section{Patients and methods}

We studied 12 patients with a mean age of 60 years (range 30-82); six had cirrhosis complicated by ascites and six congestive cardiac failure. All were taking diuretics up to the time of study. The patients with cirrhosis, four men and two women, all had alcoholic liver disease, subsequently verified by biopsy of the liver. At the time of study, however, all abstained from alcohol and had no withdrawal symptoms. All were in Pugh-Child classification grade $B$, all had moderate to tense ascites, and two had pitting oedema. None had experienced recent gastrointestinal bleeding or hepatic encephalopathy, and none had renal failure. The patients with congestive heart failure, two men and four women, all had coronary artery disease and had previously been severely decompensated (New York Heart Association functional class II or III). At the time of the study three had pitting oedema to just above ankle level, all had evidence of pulmonary oedema on initial chest radiography, and none had ascites. Three of the patients received digoxin, but none received $\beta$ blocking agents.

On the day of investigation the previous diuretic regimen was discontinued. After an overnight fast, during which the patients were not allowed to leave bed, control blood samples were collected via a cannula in the antecubital vein at $7 \mathrm{am}$, and control values for heart rate and arterial blood pressure were recorded. Then the patients emptied their bladders and drank 
$300 \mathrm{ml}$ water. At 8 am the urine output in the control hour was determined, and they were each given $1 \mathrm{mg}$ bumetanide intravenously. After randomisation by sealed envelope patients were assigned to either continuous bed rest or normal daily activity - that is, walking, sitting, etc-and food and drink were withheld.

For the next six hours on the hour urine was collected and blood samples were taken (in the supine position for recumbent patients and in the sitting position for ambulant patients). The following values were recorded: diuresis, arterial blood pressure, heart rate, and urine and serum concentrations of sodium, potassium, and creatinine. Plasma concentrations of

TABLE I-Mean values (and SEM) for urinary excretion during six hours after I mg intravenous bumetanide in six patients with decompensated cirrhosis and six patients with congestive heart failure. Glomerular filtration rate was calculated in the last two hours of study; heart rate and arterial blood pressure were recorded as an average in the six hour study period

\begin{tabular}{lcccccc}
\hline & $\begin{array}{c}\text { Cumulated } \\
\text { diuresis } \\
(\mathrm{ml} / 6 \mathrm{~h})\end{array}$ & $\begin{array}{c}\text { Urinary } \\
\text { sodium } \\
\text { excretion } \\
(\mathrm{mmol} / 6 \mathrm{~h})\end{array}$ & $\begin{array}{c}\text { Urinary } \\
\text { potassium } \\
\text { excretion } \\
(\mathrm{mmol} / 6 \mathrm{~h})\end{array}$ & $\begin{array}{c}\text { Glomerular } \\
\text { filtration } \\
\text { rate } \\
(\mathrm{ml} / \mathrm{min})\end{array}$ & $\begin{array}{c}\text { Heart rate } \\
\text { (beats/min) }\end{array}$ & $\begin{array}{c}\text { Mean } \\
\text { arterial } \\
\text { blood } \\
\text { pressure } \\
(\mathrm{mm} \mathrm{Hg})\end{array}$ \\
\hline Susition & $1133(127)$ & $96(17)$ & $25(3)$ & $100(9)$ & $76(4)$ & $86(6)$ \\
Upright & $626(91)$ & $45(10)$ & $24(3)$ & $66(7)$ & $83(5)$ & $85(8)$ \\
\hline Significance $(\mathrm{p})$ & $<0.01$ & $<0.01$ & NS & $<0.01$ & $<0.01$ & NS \\
\hline
\end{tabular}

Conversion: SI to traditional units-Sodium: $1 \mathrm{mmol}=1 \mathrm{mEq}$. Potassium: $1 \mathrm{mmol}=1 \mathrm{mEq}$.

noradrenaline, renin, and aldosterone were measured in the control hour and at one and six hours after the administration of diuretic. The glomerular filtration rate was calculated from the concentrations of serum and urine creatinine during the final two hours of study. The second day was a day of rest in which the patients continued their usual diuretic treatment, and on the third day the procedure was repeated with each patient assigned to the other posture. In this way each patient served as his own control.

Creatinine, sodium, and potassium concentrations were determined by autoanalyser (SMAC-Technicon). The concentration of plasma renin was measured by radioimmunoassay of generated angiotensin I, after incubation with heterologous substrate, the interassay variation being $8 \%$ (Medi-Lab). Plasma aldosterone was measured by a radioimmunoassay with charcoal period the total potassium excretion was roughly equal in the supine and 0 upright positions ( $p>0.05$, table I).

The resting mean arterial blood pressure did not change after intravenous bumetanide was given to the patient in either position, but the glomerular filtration rate was significantly greater in the supine position $(p<0.01$, table $C$ I). The average heart rate was unchanged after intravenous bumetanide $\widehat{\widehat{\Omega}}$ during bed rest, although on change to upright position an immediate and $\overline{ }$ maintained increase was observed. Plasma concentrations of noradrenaline $D$ (figure) were raised: mean $2 \cdot 0(0 \cdot 4) \mathrm{nmol} / \mathrm{l}(330(70) \mathrm{ng} / \mathrm{l})$. (In our laboratory $\mathbb{D}$ this is within the normal range for this age group, $0 \cdot 82-3 \cdot 10 \mathrm{nmol} / 1(140-520 \mathrm{~m}$ $\mathrm{ng} / \mathrm{l})$, but significantly above the mean values of $1.22(0.3)$ and $1.42(0.5)$ $\mathrm{nmol} / \mathrm{l}$ previously recorded, $\mathrm{p}<0.05$.) The plasma concentration rose to 3.0 $(0.65)$ and $3.8(0.60) \mathrm{nmol} / \mathrm{l}(500(110)$ and $640(100) \mathrm{ng} / \mathrm{l})$ at one and six $\mathscr{S}$ hours after bumetanide administration and change to erect position 0 $(p<0.05)$, although no change was found in the supine position after $\frac{\sigma}{\sigma}$ intravenous bumetanide.

The mean renin concentration (figure) was $241(107) \mathrm{mU} / \mathrm{l}$ in the supine $\stackrel{\overparen{D}}{\mathrm{D}}$ position, which is significantly above the normal reference range: $6-36 \mathrm{mU} / 1$. 은 After intravenous bumetanide and during continuous bed rest there was a significant decrease after six hours. On the day of upright position the mean $\vec{\circ}$ plasma renin concentration increased from $230(73)$ to $386(127)$ and 407 . (130) $\mathrm{mU} / 1$ one and six hours respectively $(p<0.05)$ after intravenous $\vec{\omega}$ bumetanide. The mean plasma aldosterone concentration (figure) was similarly raised in the control hour to $427(64) \mathrm{pmol} / \mathrm{l}(154(23) \mathrm{ng} / \mathrm{l})($ normal $\mathrm{O}$ reference range $<280 \mathrm{pmol} / \mathrm{l}(<100 \mathrm{ng} / \mathrm{l}))$. After bumetanide but during continuous bed rest there was a decrease after one and six hours respectively, but on the day of upright position the plasma aldosterone concentration rose N from $467(89)$ to 610 (97) and $601(96) \mathrm{pmol} / \mathrm{l}(168(32)$ to $220(35)$ and 216 (35 o $\mathrm{ng} / \mathrm{l})$ after one and six hours respectively $(\mathrm{p}<0.05)$.

\section{Discussion}

Our study shows that a diuretic drug may have a greater effect $\underset{\perp}{N}$ during bed rest than during normal daily activity. Moreover, the $z$ results indicate that the increased sodium reabsorption in the nephron among upright oedematous patients may be caused by the $\vec{\theta}$ further activation of nervous and hormonal sodium retaining $\&$ mechanisms as well as a decreased glomerular filtration rate. ${ }^{45}$ In a healthy person a change in posture from the recumbent position results in a reduction of the central blood volume and a consequent activation of low pressure baroreceptors on the venous side of the circulation and high pressure baroreceptors on the arterial side. ${ }^{67}$

\begin{tabular}{|c|c|c|c|c|c|c|c|c|c|c|c|c|c|}
\hline \multirow[b]{2}{*}{ Hours } & \multicolumn{2}{|c|}{0} & \multicolumn{2}{|c|}{1} & \multicolumn{2}{|c|}{2} & \multicolumn{2}{|c|}{3} & \multicolumn{2}{|r|}{4} & \multicolumn{2}{|c|}{5} & 6 \\
\hline & Supine & Supine & Upright & Supine & Upright & Supine & Upright & Supine & Upright & Supine & Upright & Supine & Upright Supine \\
\hline \multirow{2}{*}{$\begin{array}{l}\text { Urine }(\mathrm{ml} / \mathbf{h}) \\
\text { Sodium } \\
\mathrm{mmol} / \mathbf{h}\end{array}$} & $75(19)$ & $69(20)$ & $206(26)$ & $286(53)$ & $169(26)$ & $333(47)$ & $113(31)$ & $208(33)$ & $69(24)$ & $151(27)$ & $44(16)$ & $79(7)$ & $22(8) \quad 76(9)$ \\
\hline & $4 \cdot 9(1 \cdot 1)$ & $5 \cdot 9(2 \cdot 3)$ & $14 \cdot 8(2 \cdot 7)$ & $26 \cdot 6(5 \cdot 9)$ & $12 \cdot 2(2 \cdot 6)$ & $28 \cdot 1(5 \cdot 8$ & $8 \cdot 1 ! 1 \cdot 9$ & $16 \cdot 7(4)$ & $5.3(1.9)$ & $12 \cdot 3(3 \cdot 0)$ & $4 \cdot 2(1 \cdot 0)$ & $6.9) 1.5$ & $1.0(0.4) 5.2(1.1)$ \\
\hline
\end{tabular}

Sodium: $1 \mathrm{mmol}=1 \mathrm{mEq}$

column separation after thin layer chromatography, the interassay variation being $11 \%$ (Medi-Lab). Plasma noradrenaline was determined by an enzymatic isotope derivative technique as previously described with an interassay variation of $7 \% .^{3}$ Results are given as mean and SEM. The significance of differences between data in the different positions was tested by Wilcoxon's test for paired data.

\section{Results}

In all but one patient the total six hour diuresis was greater in the supine than in the upright position. The average cumulated urine excretion during the six hours was significantly larger in the supine position (table I). In either position the greatest increase in urine excretion was observed during the first and second hours after intravenous bumetanide (table II). Like the diuresis, the average natriuresis in the control hour was equal on the day of bed rest and on the day of upright position. Again the greatest natriuretic response was observed in the first and second hours after intravenous bumetanide (table II). The average cumulated sodium excretion was greater in the supine position than in the upright position (table I). During the six hour study
This causes activation of several homoeostatic mechanisms in order to secure normal perfusion pressure in the most vital areas of the circulation, the brain and heart, ${ }^{8}$ and the blood flow to the visceral 5 organs decreases by $20-30 \%$.

The most important of the known homoeostatic measures are $\bar{\sigma}$ increased sympathetic nervous activity, ${ }^{410}$ activated renin-angio- 0 tensin-aldosterone system, ${ }^{711}$ and increased release of vasopressin..$^{12} \frac{\overbrace{}}{\Phi}$ In decompensated cirrhosis, as well as in cardiac failure, the activity $\stackrel{\mathscr{C}}{+}$ of these systems - which enhance sodium reabsorption in the renal 0 tubules-is significantly increased. ${ }^{13-1^{-}}$In patients with cirrhosis the increased plasma noradrenaline concentration, an index of $\stackrel{\mathbb{Q}}{\mathscr{Q}}$ sympathoadrenal activity, has been found to be negatively correlated $\stackrel{\square}{\Omega}$ with the renal blood flow ${ }^{18}$ as well with the sodium excretion during a water load..$^{19}$ In patients with heart failure it has been directly 0 related to the degree of ventricular dysfunction. ${ }^{13221}$ Increased $\frac{0}{0}$ sympathetic nervous activity reduces renal blood flow, glomerular filtration rate, and thus sodium excretion in both conditions, ${ }^{22}$ but $\stackrel{\partial}{\rightleftharpoons}$ sodium reabsorption in the proximal tubules may be increased also 

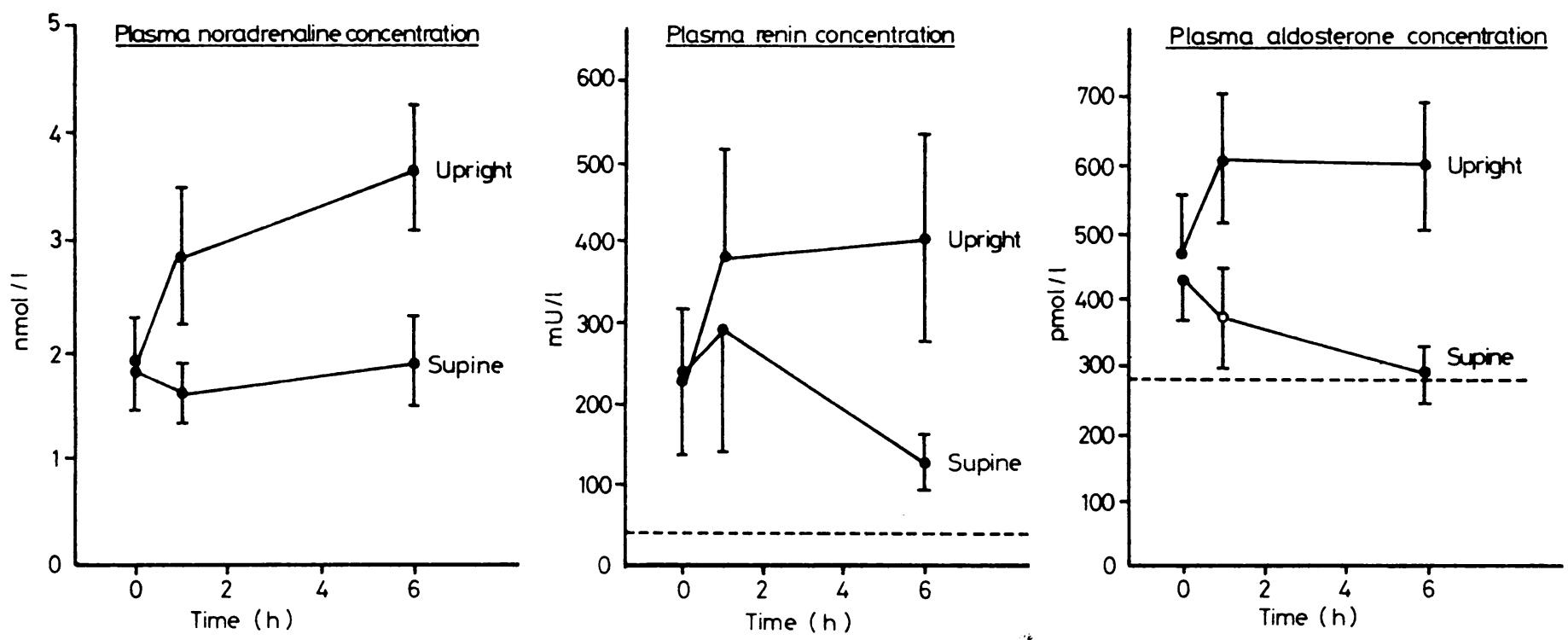

Mean plasma noradrenaline, renin, and aldosterone concentrations at rest in the supine position ( 0 hour) and one and six hours after intravenous bumetanide in the supine and upright positions. Dotted line $=$ upper limit of normal range.

by the sympathetic nervous action directly on the tubules, independently of blood flow and glomerular filtration rate. ${ }^{23.25}$

Renin activity is also increased in decompensated cirrhosis as well as in congestive heart failure. ${ }^{26-28}$ The renin-angiotensin system is important for the glomerular-tubular balance, securing filtration at low levels of blood pressure, but it probably does not directly influence tubular sodium reabsorption. ${ }^{29}$ Reduction in urinary sodium excretion has been found to be inversely related to the increase in plasma aldosterone concentration in patients with cirrhosis while sitting. ${ }^{26}$ Such a relation was also seen in our findings. The total urinary potassium excretion, however, was similar in the two positions, which may indicate that the increase in serum aldosterone concentration was of only minor importance for the increased sodium reabsorption.

Noskov investigated the contributory diuretic effect of a change of posture in normal subjects, comparing the upright posture with an antiorthostatic position-that is, $20^{\circ}$ "feet up" position, simulating weightlessness. ${ }^{30}$ The result, in an eight hour period, was an overall increase in diuresis of $53 \%$. The contributory diuretic effect of change of posture in our study was greater probably because our patients had sodium and water retention, unlike those studied by Noskov, who were in sodium balance.

Bed rest per se may have an effect on the reabsorption, distribution, and excretion of a drug given orally as well as parenterally.$^{31}$ Loop diuretics are excreted in the kidney by filtration and proximal tubular secretion and apparently act from the inside of the nephron in the ascending limb of the loop of Henle. Thus an increased glomerular filtration rate in the supine position might facilitate the bioavailability of the drug. Such an effect is probably fairly insignificant, however, except in patients with extremely low glomerular filtration rates.

In conclusion, the supine position used intermittently-for example, in the first couple of hours after a dose of diuretic-may still be valuable as it precipitates a faster mobilisation of oedema and ascites. Whether this effect may influence the marginal response in so called diuretic resistant ascites or oedema remains to be tested.

We thank Dr Steen Müllertz, department of clinical chemistry, Hvidovre Hospital, and his staff for performing most of the biochemical analyses.

\section{References}

1 Naranjo CA, Pontigo E, Valdenegro C, Gonzalez G, Ruiz I, Busto U. Furosemide-induced adverse reactions in cirrhosis of the liver. Clin Pharmacol Ther 1979;25:154-60.

2 Grantham JJ, Chanko AM. The physiologic basis and clinical use of diuretics. In: Brenner BM, Stein JH, eds. Sodium and water homeostasis. New York: Churchill Livingstone, 1978: Stein $\mathrm{JH}$
3 Christensen NJ, Vestergaard P, Sorensen T, Rafaelsen OJ. Cerebrospinal fluid adrenaline and noradrenaline in depressed patients. Acta Psychiatr Scand 1980;61:178-82.

4 Brun C, Knudsen EOE, Raaschou F. The influence of posture on the kidney function: $I$. The fall of the diuresis in the erect posture. Acta Med Scand 1945;120:315-31.

5 Brun C, Knudsen EOE, Raaschou F. The influence of posture on the kidney function. II. Acta Med Scand 1945;122:332-41.

6 Molzahn M, Dissman TH, Halim S, Lohmann F, Velkers W. Orthostatic changes of haemodynamics, renal function, plasma catecholamines and plasma renin concentration in normal and hypertensive man. Clin Sci 1972;42:209-22.

7 Hesse B, Ring-Larsen H, Nielsen I, Christensen NJ. Renin stimulation by passive tilting: the influence of an anti-gravity suit on postural changes in plasma renin activity, plasma infuence of an anti-gravity suit on postural changes in plasma renin activity, plasma
noradrenaline concentration and kidney function in normal man. Scand f Clin Lab Invest 1978;38:163-9.

8 Zelis R, Longhurst J, Capone RJ, Garrett L. Peripheral circulatory control mechanisms in congestive heart failure. Am $\mathcal{f}$ Cardiol 1973;32:481-90.

9 Mathias CJ, Christensen NJ, Corbett JL, Franker HL, Goodwin TJ, Peart NS. Plasma catecholamines, plasma renin activity and aldosterone in tetraplegic man, horizontal and tilted. Clin Sci Mol Med 1975;49:291-9.

10 Burke $D$, Sundlof $G$, Wallin BG. Postural effects on muscle nerve sympathetic activity in man. f Physiol Lond : 1977;272:399-414.

11 Oparil S, Vassaux C, Sanders CA, Haber E. Role of renin in acute postural homeostasis. Circulation 1970;41:89-95.

12 Vokes T, Robertson GL. Physiology of secretion of vasopressin. In: Czernichow P, Robinson AC, eds. Frontiers of hormone research. 13. Basle: Karger, 1985.

13 Thomas JA, Marks BM. Plasma norepinephrine in congestive heart failure. Am $\mathcal{J}$ Cardiol 1978;41:233-43.

14 Skorecki KL, Brenner BM. Body fluid homeostasis in congestive heart failure and cirrhosis with ascites. Am J Med 1982;72:323-38.

15 Francis G. Neurohumoral mechanisms involved in congestive heart failure. Am 7 Cardiol 1985;55:15A-21A

16 Ring-Larsen H, Hesse B, Henriksen JH, Christensen NJ. Sympathetic nervous activity and renal and systemic hemodynamics in cirrhosis. Plasma norepinephrine concentration, hepatic extraction and renal release. Hepatology 1982;3:56-64

17 Henriksen JH, Christensen NJ, Ring-Larsen H. Noradrenaline and adrenaline concentrations in various vascular beds in patients with cirrhosis. Relations to haemodynamics. Clin Physiol $1981 ; 1: 293-304$.

18 Ring-Larsen H, Henriksen JM, Christensen NJ. Increased sympathetic activity in cirrhosis. N Engl F Med 1983;308:1029-30.

19 Bichet D, Van Putten VJ, Schrier RW. Potential role of increased sympathetic activity in impaired sodium and water excretion in cirrhosis. N Engl f Med 1982;307:1152-7.

20 Swedberg K, Viquerat C, Rouleau J-L, et al. Comparison of myocardial catecholamine balance in chronic congestive heart failure and in angina pectoris without failure. Am 7 Cardiol $1984 ; 54: 783-6$

21 Cohn JN, Levine TB, Olivari MT, et al. Plasma norepinephrine as a guide to prognosis in patients with chronic congestive heart failure. N Engl f Med 1984;311:819-23.

22 Cannon PJ. The kidney in heart failure. N Engl f Med 1977;296:26-32.

23 Dibona GF. The functions of the renal nerves. Rev Physiol Biochem Pharmacol 1982;94:75-81.

23 Dibona GF. The functions of the renal nerves. Rev Physiol Biochem Pharmacol 1982;94:75-81. Bello-Reuss E, Trevino DL, Gottschalk CW. Effect of renal sympathetic
proximal water and sodium reabsorption. $\mathcal{F}$ Clin Invest 1976;57:1104-7.

25 Dibona GF. Neurogenic regulation of renal tubular sodium reabsorption. Am 7 Physiol 1977;233:F73-F81.

26 Bernardi M, Santini C, Trevisani F, Baraldini M, Ligabue A, Gasbarrini G. Renal function impairment induced by change in posture in patients with cirrhosis and ascites. Gut 1985;26:629-35.

27 Cody RJ, Franklin KW, Kluger J, Laragh J. Mechanisms governing the postural response and baroreceptor abnormalities in chronic congestive heart failure: Effects of acute and long term converting-enzyme inhibition. Circulation 1982;66:135-42.

28 Levine TB, Francis GS, Goldsmith SR, Cohn JN. The neurohumoral and hemodynamic response to orthostatic tilt in patients with congestive heart failure. Circulation 1983;67:1070-5.

29 Brunner HR, Gavras H. Is the renin system necessary? Am f Med 1980;69:739-45.

30 Noskov VB. Effect of body position and diuretic administration on water and mineral balance and renal activity. Hum Physiol 1982;8:288-91.

31 Halim S, Lohmann FW, Velkers W, Levy G. Effect of bed rest on distribution and elimination of drugs. F Pharm Sci 1967;56:928-9.

(Accepted 25 March 1986) 